Note

\title{
Cytogenetic analysis of the Amazon stingless bee Melipona seminigra merrillae reveals different chromosome number for the genus
}

\author{
Izaura Bezerra Francini ${ }^{1}$, Maria Claudia Gross ${ }^{2}$, Carlos Gustavo Nunes-Silva ${ }^{3,4}$, Gislene Almeida \\ Carvalho-Zilse ${ }^{1 *}$ \\ ${ }^{1} I N P A$ - Coordenação de Pesquisas em Ciências Agronômicas - Grupo de Pesquisas em Abelhas, Av. André Araújo \\ 2936 - 69060-001 - Manaus, AM - Brasil. \\ ${ }^{2} U F A M / I n s t$. de Ciências Biológicas - Lab. de Citogenômica Animal - Av. General Rodrigo Otávio, 3000 - 69077- \\ 000 - Manaus, AM - Brasil. \\ ${ }^{3}$ UFAM/Inst. de Ciências Biológicas - Centro de Apoio Multidisciplinar. \\ ${ }^{4}$ Centro Universitário Nilton Lins - Lab. Entomologia Aplicada, Av. Professor Nilton Lins, 3259 - 69058-030 - \\ Manaus, $A M-$ Brasil. \\ *Corresponding author < gislene@inpa.gov.br> \\ Edited by: Gerson Barreto Mourão
}

\begin{abstract}
Cytogenetic analysis of the Amazon stingless bee Melipona seminigra merrillae, by conventional Giemsa staining and C-banding, revealed a different chromosome number for Melipona: $2 \mathrm{n}=22$ for females and diploid drones while the haploid drones present $\mathrm{n}=11$. There is no evidence of $\mathrm{B}$ chromosomes. This result contrasts with previous studies, in which the chromosome number of 19 Melipona species was determined as $2 \mathrm{n}=18$ for females and $\mathrm{n}=9$ for haploid males. Based on cytogenetic information available for other Melipona species, we propose that M. s. merrillae has a more derived diploid number. This indicates that chromosome number is not a conservative characteristic within the genus as previously thought. Cytogenetic data for stingless bees are scarce, especially in Amazon region. Additional studies will be very important in order to promote Melipona karyoevolution discussion and consequently a taxonomy review.

Keywords: Meliponini, Neotropics, cytogenetics, diploid male chromosomes
\end{abstract}

\section{Introduction}

The majority of the stingless bee species from the Meliponini tribe are represented by Melipona Illiger, 1806 genus (Camargo and Pedro, 2008). Although widely distribute throughout the Neotropics (Michener, 2007) and found in all Brazilian States, Melipona species richness is higher in the Amazon basin region, where possibly many of them still undescribed (Silveira et al., 2002). The stingless bees, as a group, are relating to forest environments (Brosi, 2009) being one of the main native pollinators (Michener, 2007), besides some species are important in crop and greenhouse pollination as well (Heard, 1999; Nicodemo et al., 2009; Slaa et al., 2006). Cytogenetically, Melipona is the beststudied genus of the Meliponini, with 19 species studied so far, all presenting $2 \mathrm{n}=18$ chromosomes for females and $\mathrm{n}=9$ for males (Rocha et al., 2007).

Melipona seminigra merrillae Cockerell, 1919, is an abundant bee in Central Amazon (Camargo and Pedro, 2008). It is a honey-producing species and one of the most reared by Amazonian people in Meliponiculture, which is a significant activity for biodiversity conservation and local economic development (Cortopassi-Laurino et al., 2006). In this study, a different chromosomes number for $M$. s. merrillae in an urban population was described, being an important contribution for cytogenetic of Melipona also Hymenoptera.

\section{Materials and Methods}

Cytogenetic analysis was carried out on 81 individuals (40 fe- males-workers, 36 haploid males and 5 diploid males), from ten hives of Melipona seminigra merrillae, in an urban population at Manaus, state of Amazonas, Brazil (3 05.838' S, 59 59.103' W) from August to October 2008. Mitotic chromosomal preparations were obtained based on the technique described in Imai et al. (1988), by using cerebral ganglion of pink-eyed pupae. The bees' pupae dissected under a stereomicroscope (40x) and the cerebral ganglions isolated and immersed in hypotonic solution of colchicine-citrate $0.005 \%$ for one hour and twenty minutes. All chromosomal preparations were stained with Giemsa solution $5 \%$ for $20 \mathrm{~min}$. The constitutive heterochromatin was detected according to Sumner (1972). The metaphases was observed with a microscope (100x) and photographed with a digital camera (Sony DSC-W150). An average of 30 metaphases per individual was analyzed.

\section{Results and Discussion}

All analyzed females and diploid drones of Melipona seminigra merrillae showed a diploid number of $2 \mathrm{n}=22$ (Figure 1a and c) while all haploid drones were $\mathrm{n}=11$ (Figure 1b), without evidence of $\mathrm{B}$ chromosomes. Although deserving more detailed analysis, the karyotype of Melipona seminigra merrillae seems to consist of four pairs of metacentric, six pairs of submetacentric and one pair of acrocentric chromosomes. Melipona species present two patterns in heterochromatin distribution, the Type I showing C-bands around the pericentromeric region and the Type II with heterochromatin distributed along all chromosomes and/or terminally (Rocha et al., 2007). Melipona 


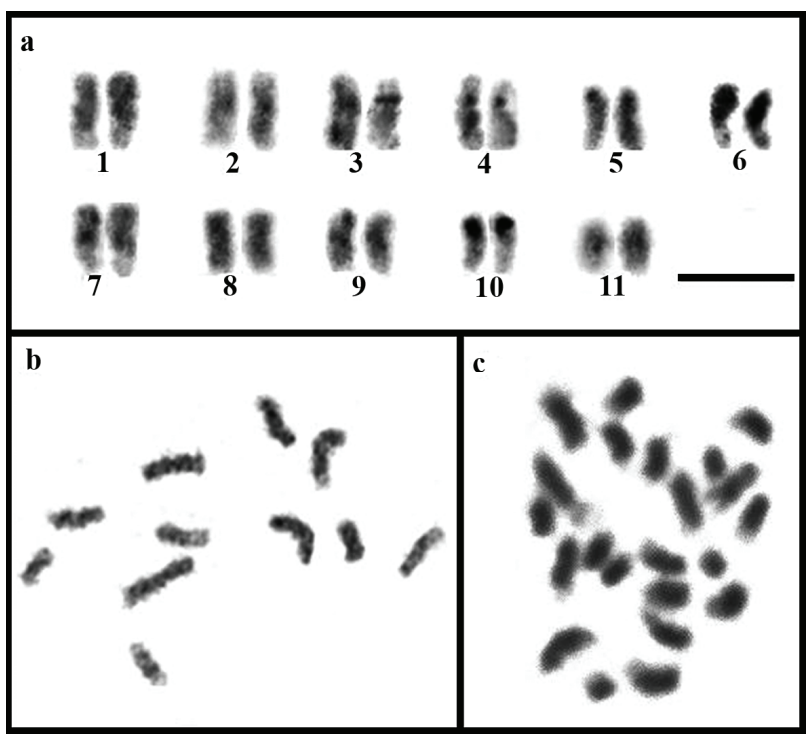

Figure 1 - Melipona seminigra merrillae: a. Female karyotype in C-banding (showing $2 \mathrm{n}=22$ ) b. Metaphase in Giemsa of male (showing $n=11$ ); c. Metaphase in Giemsa of diploid male (showing $2 \mathrm{n}=22$ ) (Bar: $5 \mu \mathrm{m})$.

seminigra merrillae seems to present heterochromatin distributed according to Type I as evidenced by conspicuous blocks in the pericentromeric region and short arms of the $6^{\text {th }}$ and $10^{\text {th }}$ chromosome pairs (Figure 1a).

Since the first karyotype described to Melipona (Kerr, 1948) to the present, the chromosome number available for all Melipona species was conservative, all of them presenting $2 \mathrm{n}=$ 18 (females) and $\mathrm{n}=9$ (males) (Rocha et al., 2007). Variations in the number of chromosomes were registered for Melipona quinquefasciata Lepeletier, 1836 (Rocha et al., 2007) and Melipona rufiventris Lepeletier, 1836 (Lopes, 2008), but these variations were attributed to the presence of B chromosomes. Thereby the results observed for M. s. merrillae contrast with the current view that chromosome number is conservative in Melipona (Rocha et al., 2007).

Cytogenetic data for stingless bees are scarce, especially in the Amazon region. Only Melipona interrupta manaosensis Schwarz, 1932 (as Melipona compressipes manaosensis) was cytogenetically studied so far (Kerr, 1952). Other two species had also been cytogenetically characterized but from sample collected in Acre state (Rocha and Pompolo, 1998; Rocha et al., 2002).

M. s. merrillae is considered to be one of the seven geographic subspecies of Melipona seminigra Friese, 1903, and an endemic bee of Amazonas state, Brazil (Camargo and Pedro, 2008). The higher chromosomes number of M. s. merrillae reflects its more derived status in relation to other Melipona species for which cytogenetic information is available (Kerr and Silveira, 1972; Hoshiba and Imai, 1993; Rocha et al., 2002).

These are very important and intriguing results, especially due to the diploid males'methaphase presented. Therefore, additional cytogenetic analyses on Melipona species will certainly clarify the evolutionary relationship among species and lead to a better understanding of the modifications in the Meliponini karyotype. Furthermore, it will contribute to the identification of species, which will certainly be useful for information regarding the biodiversity conservation and ecological pollination dynamics in the Central Amazon.

\section{Acknowledgements}

To Dra. E. Feldberg, for providing essential laboratory resources. Research grants were provided by FAPEAM, FINEP and CNPq.

\section{References}

Brosi, B.J. 2009. The complex responses of social stingless bees (Apidae: Meliponini) to tropical deforestation. Forest Ecology Management258: $1830-1837$.

Camargo, J.M.F.; Pedro, S.R.M. 2008. Meliponini Lepeletier, p. 1836. In: Moure, J.S.; Urban, D.; Melo, G.A.R., eds. Catalogue of bees (Hymenoptera, Apoidea) in the Neotropical Region. Available at: http:/ / www.moure.cria.org.br/catalogue [Accessed Nov. 16, 2009]

Cortopassi-Laurino, M.; Imperatriz-Fonseca, V.L.; Roubik, D.W.; Dolin, A.; Heard, T.; Aguilar, I.; Venturieri, G.C.; Eardley, C.; Nogueira-Neto, P. 2006. Global meliponiculture: challenges and opportunities. Apidologie 37: 275-292.

Heard, T.A. 1999. The role of stingless bees in crop pollination. Annual Review of Entomology 44: 183-206.

Hoshiba, H.; Imai, H.T. 1993. Chromosome evolution of bees and wasps (Hymenoptera, Apocrita) on the basis of C-banding pattern analyses. Japanese Journal of Entomology 61: 465-492.

Imai, H.T.; Taylor, R.W.; Crosland, M.W.J.; Crozier, R.H. 1988. Modes of spontaneous chromosomal mutation and karyotype evolution in ants with reference to the minimum interaction hypothesis. Japanese Journal of Genetics 63: 159-185.

Kerr, W.E. 1948. Studies about the Melipona genus. Anais da Escola Superior de Agricultura Luiz de Queiroz 5: 182-276 (in Portuguese).

Kerr, W.E. 1952. The variation in the number of chromosomes in the evolution of the Hymenoptera. Scientiae Genetica 4: 182-190 (in Portuguese).

Kerr, W.E.; Silveira, Z.V. 1972. Karyotypic evolution of bees and corresponding taxonomic implications. Evolution 26: 197-202.

Lopes, D.M. 2008. Cytogenetic characterization of Melipona rufiventris Lepeletier 1836 and Melipona mondury Smith 1863 (Hymenoptera, Apidae) by $\mathrm{C}$ banding and fluorochromes staining. Genetics and Molecular Biology 31: 49-52.

Michener, C.D. 2007. The Bees of the World. 2ed. Johns Hopkins University Press, Baltimore, MD, USA.

Nicodemo, D.; Couto, R.H.N.; Malheiros, E.B.; De Jong, D. 2009. Honey bee as an effective pollinating of pumpkin. Scientia Agricola 66: 476-480.

Rocha, M.P.; Pompolo, S.G. 1998. Karyotypes and heterochromatin variation (C-bands) in Melipona species (Hymenoptera, Apidae, Meliponini) chromosomes. Genetics and Molecular Biology 21: 41-45.

Rocha, M.P.; Pompolo, S.G.; Dergan, J.A.; Fernandes, A.; Campos, L.A.O. 2002. DNA characterization and karyotypic evolution in the bee genus Melipona (Hymenoptera, Meliponini). Hereditas 136:19-27.

Rocha, M.P.; Pompolo, S.G.; Fernandes, A.; Campos, L.A.O. 2007. Melipona: Six decade of cytogenetic. Bioscience Journal Supplement 1: 111-117 (in Portuguese, with abstract in English).

Silveira, F.A.; Melo, G.A.R.; Almeida, E.A.B. 2002. Brazilian Bees: Systematic and Identification. Araucária Foundation, Belo Horizonte, MG, Brazil (in Portuguese).

Slaa, E.J.; Chaves, L.A.S.; Malgodi-Braga, K.S.; Hofstede, F.E. 2006. Stingless bees in applied pollination: practice and perspectives. Apidologie 37: 293-315.

Sumner, A.T. 1972. A simple technique for demonstrating centromeric heterochromatin. Experimental Cell Research 75:304-306.

$\overline{\text { Received April 20, }} 2010$

Accepted March 17, 2011 